\title{
In vitro propagation of Gentiana scabra Bunge - an important medicinal plant in the Chinese system of medicines
}

\author{
Shih-Hung Huang ${ }^{1}$, Dinesh Chandra Agrawal ${ }^{1}$, Fang-Sheng $\mathrm{Wu}^{3}$ and Hsin-Sheng Tsay ${ }^{1,2^{*}}$
}

\begin{abstract}
Background: Gentiana scabra Bunge commonly known as 'Long dan cao' in China has been used in traditional Chinese medicines for more than 2000 years. Dry roots and rhizome of the herb have been used for the treatment of inflammation, anorexia, indigestion and gastric infections. Iridoids and secoiridoids are the main bioactive compounds which attribute to the pharmacological properties of this plant. The species is difficult to mass propagate by seed due to the low percentage of germination and limited dormancy period. Wild populations in some locations are considered to be in the endangered category due to over exploitation.

Results: In the present study, we report an efficient micropropagation system. Shoot apices of six weeks old in vitro grown G. scabra plants were used as explants for the in vitro propagation. Induction of multiple shoots (9.1/explant) was achieved on the culture of shoot apices on half strength Murashige and Skoog's basal medium (MSBM) containing $2.0 \mathrm{mg} / \mathrm{L}^{-1}$ 6-benzylaminopurine (BA), 3\% sucrose and 0.9\% Difco agar. In vitro shoots induced profuse rooting on half strength of MSBM supplemented with $0.1 \mathrm{mg} / \mathrm{L}^{-1} 1$-naphthaleneacetic acid (NAA), 3\% sucrose and $0.3 \%$ gelrite. A two-stage ventilation closure procedure during the in vitro culture, and transparent sachet technique enhanced the survival rate of G. scabra plantlets to $96 \%$ in the greenhouse. Tissue culture plants flowered after 5 months of transfer to pots.

Conclusions: A simple and an efficient in vitro propagation protocol of Gentiana scabra Bunge by optimizing the medium composition and ventilation closure treatments has been developed. The protocol can be very useful in germplasm conservation and commercial cultivation of G. scabra plants.
\end{abstract}

Keywords: Gentiana scabra; Long dan cao; Medicinal plant; Micropropagation; Ventilation closure

\section{Background}

For centuries, plants have been used as a prime natural source of alternative medicines all over the world. This old tradition of medicinal plant application has turned into a highly profitable business in the global market, resulting in the release of a large number of herbal products. There has been an ever expanding market of herbs and herbal based medicinal preparations all over the world. Gentiana is one of the highly important groups of medicinal plants. The genus Gentiana belonging to the

\footnotetext{
* Correspondence: hstsay@cyut.edu.tw

'Department of Applied Chemistry, Chaoyang University of Technology,

Taichung, Taiwan

2Department of Agronomy, National Chung-Hsing University, Taichung,

Taiwan

Full list of author information is available at the end of the article
}

family Gentianaceae contains over 400 species widely distributed in alpine habitats in temperate regions of Asia, Europe, and America (Shimada et al. 2009). Gentiana scabra Bunge, a perennial herb grows in meadows, hillsides, forest edges and shrubs in North, East and Northeast China (Han and Wang 1993). Gentiana spp. have extensive medicinal values including antiinflammatory, analgesic, antirheumatic, antipyretic, diuretic and hypoglycemic properties (Chen et al. 2008; Sezik et al. 2005; Wani et al. 2011). Dried roots of Gentiana scabra Bunge commonly known as 'Long dan cao' in traditional Chinese herbal medicines have been used in the treatment of inflammation, anorexia, indigestion and gastric infections for over 2000 years (Tang and Eisenbrand 1992). Also, dried roots and rootstcoks have been used to eliminate damp-heat and quench the fire of the liver and gall bladder (Annonymous 2010). Gentiana 
spp. contain major active compounds like gentiopicroside, swertiamarin and loganic acid. Chemical investigation of root extract of Gentiana spp. resulted in isolation of a series of iridoids, secoiridoids, xanthones and xanthone glycosides (Aberham et al. 2011). Gentiana spp. contain some of the most bitter compounds known and is used as a scientific basis for measuring bitterness. In addition to its anti-microbial and anti-inflammatory effects, gentiopicroside in G. scabra has been shown to inhibit liver dysfunction, and promote gastric acid secretion, making it a popular ingredient in Chinese herbal medicine (Kim et al. 2009).

Due to the extensive medicinal use, wild G. Scabra plants are in huge demand resulting in its over-exploitation and decline in wild populations. In Liaoning Province of China, the species has been listed in the protected plants and considered to be under the endangered category (Li 1992). Commercial propagation of G. scabra through seed has constraints due to shorter seed dormancy period and lower rates of seed germination (Seong et al. 1995; Son et al. 1999; Wen and Yang 2010). The low survival rate (20\% to $53 \%$ ) of in vitro plantlets of G. scabra in greenhouse poses a serious challenge to growers' commercialization process (Personal communications with several growers in Taiwan). Therefore, the main objective of the study was to develop a simple and an efficient in vitro propagation method of G. scabra with a high survival rate of plantlets.

\section{Methods}

\section{Plant material}

In vitro plants of G. scabra were obtained from the Taiwan Sugar Corporation, Taiwan, and were used as the source material for the present study. Shoot apices $(1.0 \mathrm{~cm})$ excised from the six weeks old in vitro plants were used as explants.

\section{Induction of multiple shoots}

For induction of multiple shoots, explants were cultured on Murashige and Skoog's (Murashige and Skoog 1962) salts and vitamins, hereinafter referred as MS basal medium (MSBM). A range of 6-benzylaminopurine (BA) $\left(0.1,0.5,1.0\right.$ and $\left.2 \mathrm{mg} / \mathrm{L}^{-1}\right)$ and Kinetin (Kin) concentrations $\left(0.1,0.5\right.$ and $\left.1.0 \mathrm{mg} / \mathrm{L}^{-1}\right), 3 \%$ sucrose, $0.9 \%$ Difco Bacto agar (Sigma-Aldrich, St. Louis, MO) were supplemented to the MSBM. The $\mathrm{pH}$ of all the media was adjusted to $5.7 \pm 0.1$, prior addition of agar and before autoclaving for $15 \mathrm{~min}$ under $1.05 \mathrm{~kg} / \mathrm{cm}$ at $121^{\circ} \mathrm{C}$.

\section{Culture vessel and culture conditions}

Orchid culture flask, a modified Erlenmeyer-style transparent glass flask with a $3.5 \mathrm{~cm}$ opening on a nearly neckless brim, a base of $9 \mathrm{~cm}$ diameter, a height of $12 \mathrm{~cm}$, and $650 \mathrm{ml}$ capacity (Figure 1a) was used as the culture vessel. Each flask contained $100 \mathrm{ml}$ of culture medium. All the cultures were incubated at $25 \pm 2^{\circ} \mathrm{C}$ with a $16 / 8 \mathrm{~h}$ (day/night) cycle under a light intensity of $38 \mu \mathrm{mol} / \mathrm{m}^{2} / \mathrm{s}$ provided by while fluorescent tubes.

\section{Induction of rooting in in vitro shoots}

The shoots induced from shoot apexes were cultured on MSBM supplemented with two auxins, NAA (0.1, 0.5 and $\left.1.0 \mathrm{mg} / \mathrm{L}^{-1}\right)$ or IBA $\left(0.1,0.5\right.$ and $\left.1.0 \mathrm{mg} / \mathrm{L}^{-1}\right), 3 \% \mathrm{su}-$ crose and $0.3 \%$ gelrite. After 8 weeks of incubation, rooted shoots were carefully taken out of the culture vessels. Their fresh weights, number of roots and shoots, length of roots and shoots were recorded.

\section{Optimization of ventilation closures}

Different ventilation closure treatments were tested by enclosing the flask openings with the following materials: (a) 2 layers of aluminium foil (AF) (Figure 1b) $(9.5 \times 9.5 \mathrm{~cm}, 0.046 \mathrm{~mm}$ thick; Reynolds Consumer Products, Alcoa Inc., Richmond, Virginia, USA; (b) 2-4 layers of dispense papers (DP) (Figure 1c) $(9.5 \times 9.5 \mathrm{~cm}$; $0.046 \mathrm{~mm}$ thick; gas flow $0.5 \mathrm{ml} / \mathrm{s}$; made from soft and hardwood fiber at 50:50; Cheng Long Corporation, Taiwan; (c) 2 layers of aluminum foil with four holes (diameter $0.5 \mathrm{~cm}$ ) punched in the center of foil covered by 2 layers of air permeable $3 \mathrm{M}$ Nexcare tape (Figure 1d) (3 M Corp., St. Paul, MN, USA). There were total 9 ventilation closure treatments grouped into two sets: (1) Onestage, where culture vessels were closed with 2 layers of aluminum foil or 2,3,4 layers of dispense paper and the total incubation period of 8 weeks; (2) Two-stage, where each culture vessel was first closed with two layers of AF for 1, 2, 3 and 4 weeks followed by replacement of the AF with 4DP in a laminar flow cabinet and continuation of incubation for further 7, 6, 5 and 4 weeks, i.e. total 8 weeks. According to the duration of incubation periods and the container closure materials, the treatment codes were designated as listed in Table 1: (1) 2 layers of aluminum foil (AF) and incubation for 8 weeks (2AF8wk), (2) 2 layers of dispense paper (DP) for 8 weeks (2DP8wk), (3) 3 layers of DP for 8 weeks (3DP8wk), (4) 4 layers of DP for 8 weeks (4DP8wk), (5) 2 layers of AF with four holes punched in the center of foil covered by 2 layers of air permeable tape and incubation for 8 weeks (4H2AF8wk) (6) 2 layers of AF for one week then AF replaced by $4 \mathrm{DP}$ for the next 7 weeks (2AF1wk/4DP7wk), (7) 2 layers of AF for 2 weeks then AF replaced by $4 \mathrm{DP}$ for the next 6 weeks (2AF2wk/ 4DP6wk), (8) 2 layers of AF for 3 weeks then AF replaced by $4 \mathrm{DP}$ for the next 5 weeks (2AF3wk/4DP5wk), (9) 2 layers of AF for 4 weeks then AF replaced by 4 DP for the next 4 weeks (2AF4wk/4DP4wk). Thus, for all the cultures the total incubation period was kept constant, i.e. 8 weeks. Medium composition for each ventilation closure treatment consisted of half strength MSBM supplemented with $0.1 \mathrm{mg} / \mathrm{L}^{-1} \mathrm{NAA}, 3 \%$ sucrose and $0.3 \%$ gelrite. 

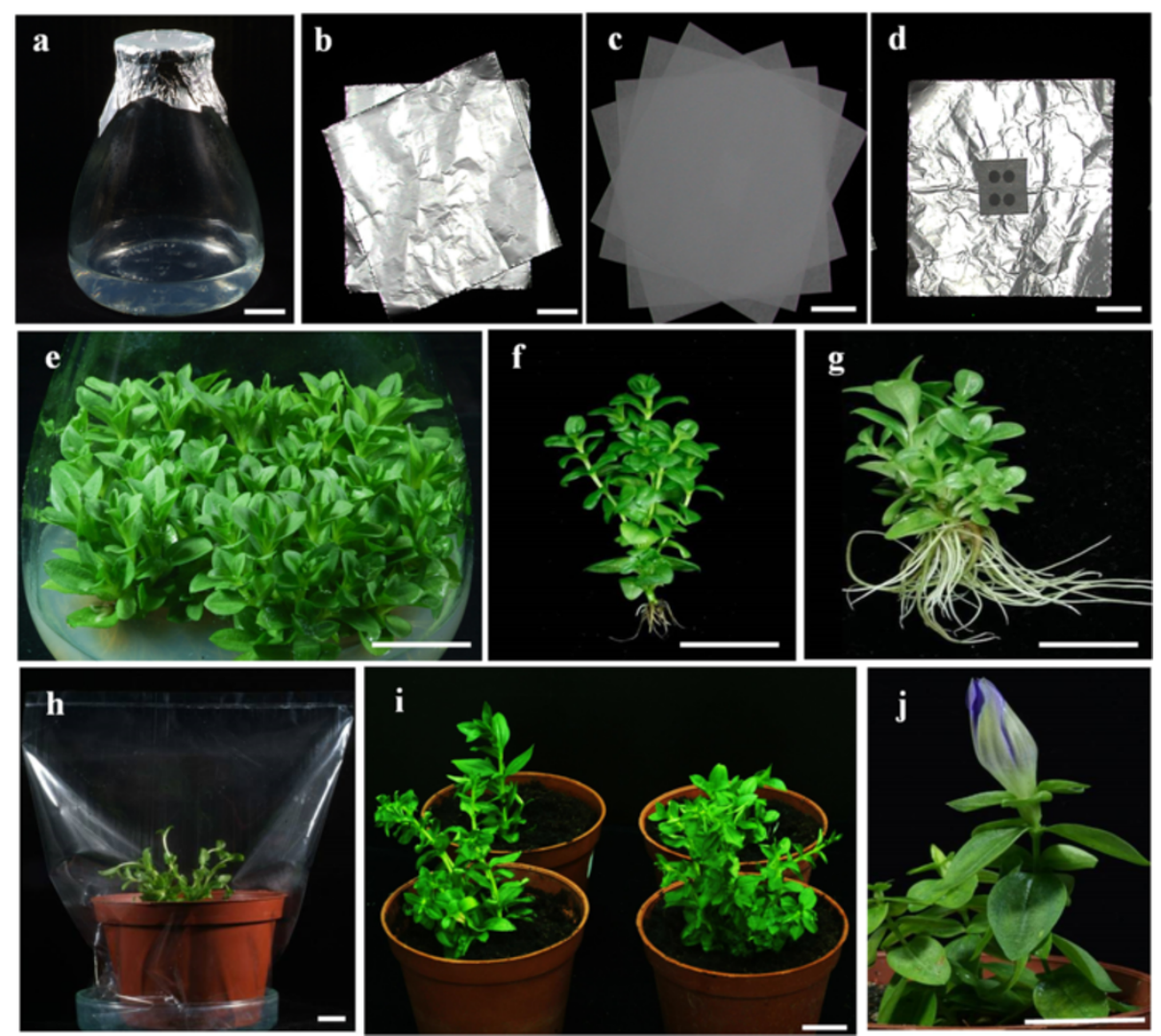

Figure 1 In vitro propagation of Gentiana scabra Bunge. a: Orchid culture flask, b: Two layers of aluminium foil (2AF), c: Four layers of dispense papers; $\mathbf{d}$ : Two layers of aluminium foils with four holes (diameter $0.5 \mathrm{~cm}$ ) punched in the center of foil and covered by 2 layers of air permeable 3 M Nexcare tape (4H2AF), e: Multiple shoots, f: Source culture obtained from Taiwan Sugar Corporation, Taiwan, g: Rooted shoots (medium with $0.1 \mathrm{mg} / \mathrm{L}^{-1} \mathrm{NAA}$ ), $\mathbf{h}$ : A potted plant covered with plastic sachet, i: Potted plants (acclimatized), $\mathbf{j}$ : Plant in the flowering stage in the University's greenhouse. Scale bar $=2 \mathrm{~cm}$

Table 1 Influence of ventilation closure types on root/shoot growth parameters and ex vitro plant survival in G. scabra Bunge ${ }^{x}$

\begin{tabular}{|c|c|c|c|c|c|c|}
\hline \multicolumn{2}{|c|}{$\begin{array}{l}\text { Ventilation closure } \\
\text { treatment code }\end{array}$} & \multirow{2}{*}{$\begin{array}{l}\text { No. of roots } \\
20.2 \pm 9.0 a\end{array}$} & \multirow{2}{*}{$\begin{array}{l}\text { Root length }^{\mathbf{Z}}(\mathrm{cm}) \\
4.58 \pm 1.16 \mathrm{a}\end{array}$} & \multirow{2}{*}{$\begin{array}{l}\text { Shoot length }^{\mathbf{Z}}(\mathbf{c m}) \\
2.23 \pm 0.69 a\end{array}$} & \multirow{2}{*}{$\begin{array}{l}\text { Fresh weight }^{\mathrm{YZ}}(\mathbf{g}) \\
1.09 \pm 0.46 \mathrm{a}\end{array}$} & \multirow{2}{*}{$\begin{array}{l}\begin{array}{l}\text { Plant survival } \\
\text { rate }^{\mathrm{z}}(\%)\end{array} \\
94.44 \pm 4.30 \mathrm{a}\end{array}$} \\
\hline One-stage & 2AF8wk & & & & & \\
\hline & 2DP8wk & $12.4 \pm 9.3 b$ & $3.03 \pm 1.18 c$ & $1.28 \pm 0.32 c$ & $0.77 \pm 0.42 c$ & $79.13 \pm 13.93 b$ \\
\hline & 3DP8wk & $13.0 \pm 7.7 b$ & $3.02 \pm 0.89 c$ & $1.43 \pm 0.31 b c$ & $0.78 \pm 0.47 c$ & $89.92 \pm 8.36 a b$ \\
\hline & 4DP8wk & $18.0 \pm 10.2 \mathrm{a}$ & $3.78 \pm 1.01 b$ & $1.51 \pm 0.40 b$ & $0.94 \pm 0.33 b$ & $91.67 \pm 6.01 \mathrm{ab}$ \\
\hline & 4H2AF8wk & $15.9 \pm 4.98 \mathrm{a}$ & $4.25 \pm 0.92 b$ & $1.93 \pm 0.88 a$ & $0.93 \pm 0.45 a$ & $91.11 \pm 8.31 \mathrm{ab}$ \\
\hline \multirow[t]{4}{*}{ Two-stage } & 2AF1wk/4DP7wk & $23.0 \pm 9.7 b^{2}$ & $4.44 \pm 1.12 c^{z}$ & $1.89 \pm 0.42 b^{z}$ & $1.14 \pm 0.32 b^{z}$ & $91.67 \pm 2.89 a^{z}$ \\
\hline & 2AF2wk/4DP6wk & $29.6 \pm 12.0 \mathrm{a}$ & $5.78 \pm 1.13 \mathrm{a}$ & $2.31 \pm 0.59 a$ & $1.29 \pm 0.40 a b$ & $90.00 \pm 3.33 \mathrm{a}$ \\
\hline & 2AF3wk/4DP5wk & $28.6 \pm 13.5 \mathrm{a}$ & $5.15 \pm 1.20 b$ & $2.48 \pm 0.74 \mathrm{a}$ & $1.23 \pm 0.46 b$ & $93.33 \pm 4.67 \mathrm{a}$ \\
\hline & 2AF4wk/4DP4wk & $33.7 \pm 12.5 \mathrm{a}$ & $5.89 \pm 0.92 \mathrm{a}$ & $2.35 \pm 0.51 \mathrm{a}$ & $1.41 \pm 0.45 \mathrm{a}$ & $96.25 \pm 3.60 \mathrm{a}$ \\
\hline
\end{tabular}

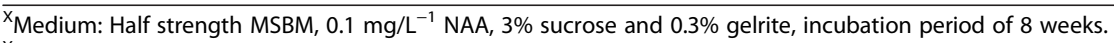

${ }^{\mathrm{Y}}$ Fresh weight of rooted shoot (plantlet).

${ }^{z}$ Means followed by the same letter of a column are not significantly different at $5 \%$ probability $(p=0.05)$ level by least significant difference (LSD) test. 


\section{Acclimatization of plantlets}

After 8 weeks of incubation under the ventilation closure conditions described above, the plantlets were carefully taken out of culture vessels and rinsed gently with running tap water to remove traces of agar. The plantlets were then blotted dry on paper towel and their fresh weights, number of shoots and roots, length of roots and shoots were recorded. Thereafter, plantlets were briefly treated with $0.1 \%$ Benlate (a systemic fungicide) solution (DuPont, Wilmington, DE) and transplanted into plastic pots containing a mixture of peatmoss:perlite:vermiculite $(2: 1: 1 \mathrm{v} / \mathrm{v})$. For acclimatization, each potted plant was covered with a transparent polyethylene sachet (Figure $1 \mathrm{~h}$ ). After one week, a small hole was made in a corner of each sachet, and another hole was made in the opposite corner after 2 weeks. The top corners on both sides of each sachet were cut open after 3 weeks, and sachets were completely removed after 4 weeks. Thereafter, these were shifted to the University's greenhouse. The plants were irrigated every day with tap water. The plant survival against each ventilation closure treatment was recorded after 2 months.

\section{Statistical analysis}

Data were analyzed statistically by using Statistical Analysis System SAS 9.1 for ANOVA and the least significant difference (LSD) tested at $5 \%$ probability level $(p \geq 0.05)$. All experiments were repeated minimum three times. There were minimum 30 replicates under each treatment.

\section{Results and discussion}

\section{Multiple shoot induction}

In our initial experiments on different strengths (1X, 1/ $2 \mathrm{X}$ and $1 / 4 \mathrm{X}$ ) of MSBM medium, it was observed that $1 / 2 \mathrm{X}$ MSBM medium resulted in the better shoot/root growth in comparison to $1 \mathrm{X}$ or $1 / 4 \mathrm{X}$ strengths (data not shown), hence, 1/2X MSBM medium was used for all the experiments. Between the two cytoknins, BA was more effective and induced a higher number of shoots per explant compared to Kin (Table 2) (Figure 1e). The maximum average number of multiple shoots (9.1 shoots/explant) could be induced in shoot apices on half strength MSBM supplemented with $2.0 \mathrm{mgL}^{-1} \mathrm{BA}, 3 \%$ sucrose and $0.9 \%$ agar, followed by 8.8 shoots/explant on medium with $1.0 \mathrm{mgL}^{-1} \mathrm{BA}$. There was an inverse correlation between concentrations of both BA and Kin and lengths of induced shoots. Average shoot elongation was higher $(2.82$ and $3.56 \mathrm{~cm})$ at lower concentrations of BA $\left(0.1 \mathrm{mgL}^{-1}\right)$ and Kin $\left(0.1 \mathrm{mgL}^{-1}\right)$, respectively (Table 2$)$. Similar to the present study, BAP was found to be the most effective cytokinin in several plant species, i.e. Gossypium (Agrawal et al. 1997), Salix (Agrawal and Gebhardt 1994), Pisum (Jackson and Hobbs 1990), Phaseolus (McClean and Grafton 1989) and Glycine (Cheng et al. 1980), indicating a particular cytokinin preference of certain tissues for the induction of multiple shoots. In an earlier report on G. scabra, induction of multiple shoots in axillary buds of was achieved on MS medium supplemented with gibberlliin $\mathrm{A}_{3}\left(\mathrm{GA}_{3}\right)$ and $\mathrm{BA}\left(1 \mathrm{mg} / \mathrm{L}^{-1}\right.$ each) (Yamada et al. 1991). In another study, adventitious buds were induced in stem callus of G. scabra cultured on MS medium supplemented with $1.2 \mathrm{mgL}^{1} \mathrm{AgNO}_{3}+0.6 \mathrm{mgL}^{1}$ $\mathrm{BA}+0.1 \mathrm{mgL}^{1} \mathrm{NAA}$ (Wen and Yang 2010).

\section{Induction of rooting in in vitro shoots}

On culture of in vitro derived shoots on $1 / 2$ strength MSBM medium supplemented with a range of concentrations of two auxins (NAA and IBA) for 8 weeks, it was observed that the lower concentrations of NAA or IBA resulted in a higher number as well as better root/shoot growth. NAA at $0.1 \mathrm{mg} / \mathrm{L}^{-1}$ induced the greater number of roots (37.2) and fresh weight (1.55 g) in comparison to IBA at $0.1 \mathrm{mg} / \mathrm{L}^{-1}$ which induced a lesser number of roots (25.8) and lesser fresh weight $(1.20 \mathrm{~g})$ (Table 3$)$. Higher concentrations of IBA and NAA $\left(1.0 \mathrm{mg} / \mathrm{L}^{-1}\right)$ reduced the number and length of roots as compared to $0.1 \mathrm{mg} / \mathrm{L}^{-1}$ concentration. In contrast to culture (Figure 1f) obtained

Table 2 Induction of multiple shoots in shoot apices of Gentiana scabra Bunge

\begin{tabular}{lllll}
\hline Cytokinin $^{\mathbf{X}}\left(\mathbf{m g} / \mathbf{L}^{-\mathbf{1}}\right)$ & & No. of shoots $^{Y}$ & Shoot length $^{Y}(\mathbf{c m})$ & Fresh weight of rooted shoot $^{\Upsilon}(\mathbf{g})$ \\
\hline BA & 0 & $5.6 \pm 0.8 \mathrm{c}$ & $4.82 \pm 0.49 \mathrm{a}$ & $0.50 \pm 0.15 \mathrm{~d}$ \\
& 0.1 & $7.1 \pm 1.0 \mathrm{~b}$ & $2.82 \pm 0.27 \mathrm{~d}$ & $0.55 \pm 0.08 \mathrm{bcd}$ \\
& 0.5 & $7.4 \pm 1.4 \mathrm{~b}$ & $2.43 \pm 0.24 \mathrm{e}$ & $0.55 \pm 0.17 \mathrm{bcd}$ \\
& 1.0 & $8.8 \pm 2.8 \mathrm{a}$ & $2.23 \pm 0.43 \mathrm{e}$ & $0.53 \pm 0.10 \mathrm{~cd}$ \\
& 2.0 & $9.1 \pm 1.8 \mathrm{a}$ & $1.92 \pm 0.42 \mathrm{f}$ & $0.53 \pm 0.17 \mathrm{~cd}$ \\
Kin & $5.5 \pm 0.9 \mathrm{c}$ & $3.56 \pm 0.31 \mathrm{~b}$ & $0.59 \pm 0.07 \mathrm{abc}$ \\
& 0.1 & $5.0 \pm 0.8 \mathrm{c}$ & $3.31 \pm 0.17 \mathrm{c}$ & $0.60 \pm 0.09 \mathrm{ab}$ \\
& 0.5 & $3.13 \pm 0.26 \mathrm{c}$ & $0.60 \pm 0.15 \mathrm{a}$ \\
\hline
\end{tabular}

- Influence of BA and Kin.

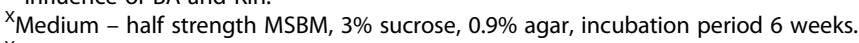

${ }^{Y}$ Means followed by the same letter of a column are not significantly different.

at $5 \%$ probability $(p=0.05)$ level by least significant difference (LSD) test. 
Table 3 Induction of rooting in in vitro shoots of G. scabra Bunge - Influence of auxins on root/shoot growth parameters ${ }^{X}$

\begin{tabular}{|c|c|c|c|c|c|}
\hline \multicolumn{2}{|c|}{ Auxin $\left(\mathrm{mg} / \mathrm{L}^{-1}\right)$} & \multirow{2}{*}{$\frac{\text { No. of roots }^{Y}}{26.5 \pm 7.3 b}$} & \multirow{2}{*}{$\frac{\text { Root length }^{Y}(\mathbf{c m})}{5.07 \pm 1.24 b}$} & \multirow{2}{*}{$\begin{array}{l}\text { Shoot length }^{\mathrm{Y}}(\mathbf{c m}) \\
3.89 \pm 1.39 \mathrm{a}\end{array}$} & \multirow{2}{*}{$\begin{array}{l}\text { Fresh weight }^{Y, Z} \text { (g } \\
0.96 \pm 0.34 \mathrm{e}\end{array}$} \\
\hline NAA & 0 & & & & \\
\hline & 0.1 & $37.2 \pm 12.1 \mathrm{a}$ & $5.83 \pm 1.03 a$ & $3.06 \pm 0.68 b$ & $1.55 \pm 0.38 a$ \\
\hline & 0.5 & $33.2 \pm 17.5 b$ & $4.51 \pm 1.14 \mathrm{C}$ & $2.65 \pm 1.17 c$ & $1.44 \pm 0.44 \mathrm{cb}$ \\
\hline & 1.0 & $25.3 \pm 22.1 b$ & $2.96 \pm 1.33 d$ & $1.58 \pm 0.96 \mathrm{~d}$ & $1.32 \pm 0.52 a b$ \\
\hline \multirow[t]{3}{*}{ IBA } & 0.1 & $25.8 \pm 6.3 b$ & $5.44 \pm 0.82 a b$ & $3.33 \pm 0.91 b$ & $1.20 \pm 0.29 \mathrm{~cd}$ \\
\hline & 0.5 & $16.2 \pm 7.5 \mathrm{C}$ & $4.55 \pm 1.47 c$ & $2.37 \pm 0.80 c$ & $1.17 \pm 0.39 \mathrm{de}$ \\
\hline & 1.0 & $12.1 \pm 5.9 \mathrm{C}$ & $4.15 \pm 1.30 c$ & $2.04 \pm 0.68 c$ & $1.15 \pm 0.36 d$ \\
\hline
\end{tabular}

Medium: half strength MSBM, 3\% sucrose and $0.3 \%$ gelrite, Incubation period of 8 weeks.

${ }^{Y}$ Means followed by the same letter of a column are not significantly different at the $5 \%$ probability $(p=0.05)$ level by least significant difference (LSD) test.

${ }^{\mathrm{Z}}$ Fresh weight of rooted shoot.

from Taiwan Sugar Corporation, roots induced in the MSBM medium supplemented with NAA $0.1 \mathrm{mg} / \mathrm{L}^{-1}$ were multifold and robust (Figure $1 \mathrm{~g}$ ). A supplement of $1.0 \mathrm{mg} / \mathrm{L}^{-1} \mathrm{NAA}$ in the MSBM stimulated callus induction, a trait undesirable for health of roots/shoots and ex vitro survival of plantlets.

Auxins are known to affect both root and shoot growth parameters and play an important role particularly in root development. Different plant species respond differently to auxins for the induction of rooting. The promotory effect of a lower salt concentration of MS on in vitro rooting of shoots has been reported for Gossypium (Agrawal et al. 1997), Philodendron spp. (Maene and Debergh 1985). Some plant species, even do not require any auxin supplemental in the medium for rooting (Agrawal and Gebhardt 1994), hence it is desirable to optimize the type and concentration of an auxin in a micropropagation protocol of a particular plant species. In contrast to our results, induction of rooting in shoots of Gentiana scabra was achieved on hormone free MS medium (Yamada et al. 1991), or on 1/2 MS medium supplemented with $0.3 \mathrm{mgL}^{1} \mathrm{NAA}+0.1$ $\mathrm{mgL}^{1}$ IAA (Wen and Yang 2010). Akin to the present study, higher concentrations of NAA induced callus in G. davidii var. formosana (Chueh et al. 2001).

\section{Optimization of ventilation closures}

Between the two sets of ventilation closure treatments, i.e. one-stage and two-stage with a total incubation period of 8 weeks, overall, all the root/shoot growth parameters including the plant survival percentage were higher with two-stage ventilation closure treatments (Table 1). There were significant differences in root/shoot growth parameters among the treatments within the one-stage, and twostage ventilation closures itself (Figure 2 a1-4 and b1-4).
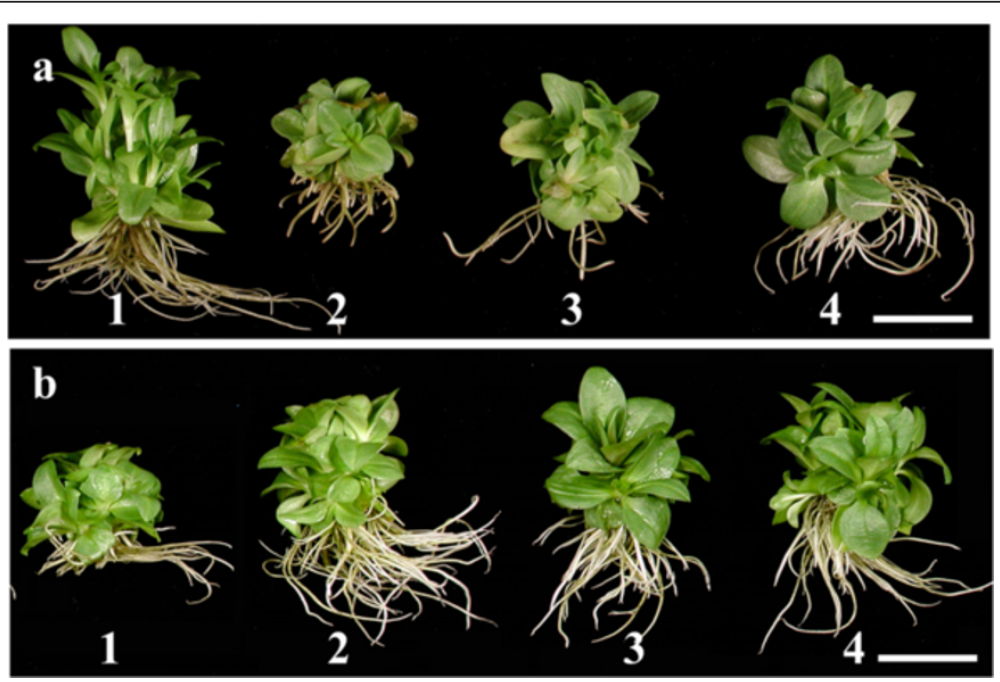

Figure. 2 Influence of ventilation closures on root/shoot growth in G. scabra Bunge (a) One-stage ventilation closure: (1) 2AF8wk-2 layers of aluminum foil (AF) and incubation for 8 weeks, (2) 2DP8wk-2 layers of dispense papers (DP) for 8 weeks, (3) 3DP8wk-3 layers of DP for 8 weeks, (4) 4DP8wk-4 layers of DP for 8 weeks, (b) Two-stage ventilation closure: (1) 2AF1wk/4DP7wk-2 layers of AF for one week then AF replaced by 4 DP for the next 7 weeks, (2) 2AF2wk/4DP6wk-2 layers of AF for 2 weeks then AF replaced by 4 DP for the next 6 weeks, (3) 2AF3wk/4DP5wk-2 layers of AF for 3 weeks then AF replaced by 4 DP for the next 5 weeks, and (4) 2AF4wk/4DP4-2 layers of AF for 4 weeks then AF replaced by 4 DP for the next 4 weeks. Scale bar $=2 \mathrm{~cm}$ 
Among the one-stage ventilation closure treatments, the maximum number of roots (20.20), root length $(4.58 \mathrm{~cm})$, shoot length $(2.23 \mathrm{~cm})$, fresh weight $(1.09 \mathrm{~g})$ and plant survival percentage (94.44) was achieved with 2AF8wk, i.e. when culture vessels were closed with 2 layers of aluminum foil and incubation for 8 weeks. In contrast to aluminum foil, there was an overall decrease in root/shoot growth parameters when culture vessels were closed with 2, 3 and 4 dispense papers. Among the three DP treatments, the maximum number of roots (18), root length $(3.78 \mathrm{~cm})$, shoot length $(1.51 \mathrm{~cm})$, fresh weight $(0.94 \mathrm{~g})$ and plant survival percentage (91.67) was achieved with 4DP8wk, i.e. when culture vessels were closed with 4 layers of dispense paper and incubation for 8 weeks. There was no drastic difference in root/shoot growth parameters and plant survival percentage in the ventilation closure treatment 4H2AF8wk, i.e. $2 \mathrm{AF}$ with 4 holes punched in the center and covered with air permeable tape. Among the 4 two-stage ventilation closure treatments, the maximum number of roots (33.7), root length $(5.89 \mathrm{~cm})$, fresh weight $(1.41 \mathrm{~g})$ and plant survival (96\%) were obtained with treatment 2AF4wk/4DP4wk, i.e. when culture vessels were closed with 2 AF for 4 weeks and then AF replaced by 4DP for the next 4 weeks (Table 1 ).

It is essential to close a culture container with some closure material to maintain sterility of the cultures. Different types of container closure materials like micropore, parafilm, and polyvinyl chloride for eggplants (Ribeiro et al. 2009), plastic films for neem (Rodrigues et al. 2012) have been used. In our laboratory, aluminum foil and dispense paper have been used successfully to improve ventilation for cultures of Scrophularia (Chen et al. 2006a), and Bupleurum (Chen et al. 2006b). It has been reported that the type of closure affects gaseous exchange, availability of water, micronutrients, and balance of hormones in the culture container (Kataeva et al. 1991; Lai et al. 2005; Chen et al. 2006a; Tsay et al. 2006). The head space of culture vessels with low ventilation, accumulates various gaseous compounds like ethylene and carbon dioxide (Akhter Zobayed et al. 2001; Lai et al. 2005). These undesirable compounds can alter biochemical responses and leaf development of in vitro cultured plants (Pierik et al. 2007) and also affect enzymes involved in oxidative activities (Synková and Pospíšilová 2002). Some closures cause restriction of gaseous exchange between the container atmosphere and the outside environment (Buddendorf-Joosten and Woltering 1994), which can result in poor aeration and hyperhydric condition of cultures. Also, growth rate and other physiological and morphological characteristics of plants developed under in vitro conditions can be influenced by the physical and chemical micro-environments of culture containers (Walker et al. 1988). Different species show different requirement with respect to container closures. Hence, it is important to optimize a closure type in a micropropagation protocol of a particular plant species. In the present study, a new approach of combining the foil and dispense paper was used for the G. scabra cultures. It was observed that aluminum foil, a less air permeable material for first 4 weeks, followed by more air permeable dispense papers for next 4 weeks was an adequate ventilation treatment for optimum root/shoot growth and subsequent survival of G. scabra plantlets.

\section{Influence of ventilation closures on survival of plantlets, and acclimatization procedure}

Between the one-stage and two-stage ventilation closure treatments, the overall survival percentages were higher (90-96) in the two-stage treatments (Table 1). The maximum survival percentage (96) was recorded with the twostage treatment 2AF4wk/4DP4wk, i.e. culture vessel closed with 2 layers of aluminum foil for first 4 weeks and then AF replaced with 4 layers of disense paper. Covering of plants with transparent polyethylene sachets for the first 4 weeks and its gradual exposure to the ambient conditions was supportive of acclimatization process and gave rise to higher plantlet survival percentages. Tissue culture plants flowered (Figure 1j) in the greenhouse after 5 months of their transfer to pots.

\section{Conclusions}

In the present study, we have developed a simple and an efficient in vitro propagation protocol of Gentiana scabra Bunge by optimizing the medium composition and ventilation closure treatments. The developed protocol may be very useful in micropropagation, germplasm conservation and commercial cultivation of G. scabra plants.

\section{Abbreviations \\ BA: 6-benzylaminopurine; IBA: Indole-3-butyric acid; MSBM: Murashige and Skoog's basal medium (MS salts and vitamins); NAA: 1-naphthaleneacetic acid.}

\section{Competing interests}

The authors declare that they have no competing interests.

\section{Authors' contribution}

SHH carried out the experimental work, DCA prepared the manuscript, FSW provided critical inputs towards the research, and HST provided laboratory facilities and supervised the research work. All authors read and approved the final manuscript.

\section{Acknowledgement}

A research grant (NSC 101-2313-B-324-001) from the National Science Council, Taiwan is gratefully acknowledged.

\section{Author details}

'Department of Applied Chemistry, Chaoyang University of Technology,

Taichung, Taiwan. ${ }^{2}$ Department of Agronomy, National Chung-Hsing

University, Taichung, Taiwan. ${ }^{3}$ Department of Biology, Virginia

Commonwealth University, Richmond, VA 23284-2012, USA. 
Received: 10 June 2014 Accepted: 4 July 2014

Published: 24 July 2014

\section{References}

Aberham A, Pieri V, Croom JEM, Ellmerer E, Stuppner H (2011) Analysis of iridoids, secoiridoids and xanthones in Centaurium erythraea, Frasera caroliniensis and Gentiana lutea using LC-MS and RP-HPLC. J Pharm Biomed Anal 54:517-525

Agrawal DC, Gebhardt K (1994) Rapid micropropagation of hybrid willow (Salix) established by ovary culture. J Plant Physiol 143(6):763-765

Agrawal DC, Banerjee AK, Kolala RR, Dhage AB, Nalawade SM, Kulkarni AV, Hazra S, Krishnamurthy KV (1997) In vitro induction of multiple shoots and plant regeneration in cotton (Gossypium hirsutum L.). Plant Cell Rep 16:647-652, doi:10.1007/BF01275508

Akhter Zobayed SM, Armstrong J, Armstrong W (2001) Leaf anatomy of in vitro tobacco and cauliflower plantlets as affected by different types of ventilation. Plant Sci 161:537-548

Annonymous (2010) Committee for the Pharmacopoeia of P.R. China. Chemical Industry Press. In: Pharmacopoeia of the People's Republic of China I. China Medical Science and Technology Press, Beijing, China

Buddendorf-Joosten JMC, Woltering EJ (1994) Components of the gaseous environment and their effects on plant growth and development in vitro. Plant Growth Regul 15:1-16

Chen UC, Hsia CN, Agrawal DC, Tsay HS (2006a) Influence of ventilation closures on plant growth parameters, acclimation and anatomy of leaf surface in Scrophularia yoshimurae Yamazaki - a medicinal plant native to Taiwan. Bot Stud 47:259-266

Chen UC, Hsia CN, Yeh MS, Agrawal DC, Tsay HS (2006b) In vitro micropropagation and ex vitro acclimation of Bupleurum kaoi - an endangered medicinal plant native to Taiwan. In Vitro Cell Dev Biol - PI 42:128-133

Chen L, Wang HB, Sun XL, Sun W (2008) Study on the analgesic and anti-inflammatory activities of Gentiopicroside. Nat Prod Res Dev 20:903-906

Cheng TY, Saka H, Voqui-Dinh TH (1980) Plant regeneration from soybean cotyledonary node segments in culture. Plant Sci Lett 19:91-99

Chueh FS, Chen CC, Sagare AP, Tsay HS (2001) Quantitative determination of secoiridoid glucosides in in vitro propagated plants of Gentiana davidii var. formosana by high performance liquid chromatography. Planta Med 67:70-73

Han QZ, Wang ZX (1993) Flora of Dalian district (Volume II). Dalian University of Science and Technology Press, Dalian, p 588p, In Chinese

Jackson JA, Hobbs SLA (1990) Rapid multiple shoot production from cotyledonary node explants of pea (Pisum sativum). In Vitro Cell Dev Biol 26:835-838

Kataeva NV, Alexanandrova IG, Butenko RG, Dragavtceva EV (1991) Effect of applied and internal hormones on vitrification and apical necrosis of different plants cultured in vitro. Plant Cell Tiss Org 14:31-40

Kim JA, Son NS, Son JK, Jahng YD, Chang HW, Jang TS, Na MK, Lee SH (2009) Two new secoiridoid glycosides from the rhizomes of Gentiana scabra Bunge. Arch Pharm Res 32(6):863-867, doi:10.1007/s12272-009-1608-0

Lai CC, Lin HM, Nalawade MS, Fang W, Tsay HS (2005) Hyperhydricity in shoot cultures of Scrophularia yoshimurae can be effectively reduced by ventilation of culture vessels. J Plant Physiol 162:355-361

Li SX (ed) (1992) Flora Liaoningica Tomus (Volume II). Liaoning Science and Technology Press, China, Shenyang, p 1179p, In Chinese

Maene L, Debergh P (1985) Liquid medium addition to established tissue cultures to improve elongation and rooting in vitro. Plant Cell Tiss Org 5:23-33

McClean P, Grafton KF (1989) Regeneration of dry bean (Phaseolus vulgaris L.) via organogenesis. Plant Sci 60:117-122

Murashige T, Skoog F (1962) A revised medium for rapid growth and bio assays with tobacco tissue cultures. Physiol Plant 15:473-497

Pierik R, Sasidharan R, Voesenek LCJ (2007) Growth control by ethylene: adjusting phenotypes to the environment. J Plant Growth Regul 26:188-200

Ribeiro APO, Picoli EAT, Lani ERG, Vendrame WA, Otoni WC (2009) The influence of flask sealing on in vitro morphogenesis of eggplant (Solanum melongena L.). In Vitro Cell Dev - PI 45:421-428

Rodrigues M, Costa TF, Festucci-Buselli R, Silva L, Otoni W (2012) Effects of flask sealing and growth regulators on in vitro propagation of neem (Azadirachta indica A. Juss). In Vitro Cell Dev - PI 48:67-72

Seong NS, Park CH, Kim KS, Lee ST, Chang YH (1995) In vitro variant induction and its content of gentiopicroside of Gentiana scabra Bunge. Korean J Med Crop Sci 3(1):40-44
Sezik E, Aslan M, Yesilada E, Ito S (2005) Hypoglycaemic activity of Gentiana olivieri and isolation of the active constituent through bioassay-directed fractionation techniques. Life Sci 76:1223-1238

Shimada N, Nakatsuka T, Nakano Y, Kakizaki Y, Abe Y, Hikage T, Nishihara M (2009) Identification of gentian cultivars using SCAR markers based on intron-length polymorphisms of flavonoid biosynthetic genes. Sci Hortic 119:292-296

Son BG, Choi YW, Ahn CK, Cho D, Kang JS, Chung YM, Kwon OC (1999) Geminability, morphological development during germination and anatomical observation in Gentiana scabra Bunge var. buergeri Max. Korean J Life Sci 9(2):127-135

Synková H, Pospíšilová J (2002) In vitro precultivation of tobacco affects the response of antioxidative enzymes to ex vitro acclimation. J Plant Physiol 159:781-789

Tang W, Eisenbrand G (1992) Chinese Drugs of Plant Origin: Chemistry, Pharmacology, and Use in Traditional and Modern Medicine. Springer, Berlin, pp 549-553

Tsay HS, Lee CY, Agrawal DC, Basker S (2006) Influence of ventilation closure, gelling agent and explant type on shoot bud proliferation and hyperhydricity in Scrophularia yoshimurae- a medicinal plant. In Vitro Cell Dev - PI 42:445-449

Walker PN, Heuser CW, Heinemann PH (1988) Micropropagation: studies of gaseous environments. Acta Hort 230:145-151

Wani B, Ramamoorthy D, Ganai B (2011) Preliminary phytochemical screening and evaluation of analgesic activity of methanolic extract of roots of Gentiana kurroo royle in experimental animal models. Int J Pharm Sci 3:164-166

Wen W, Yang J (2010) Study on the tissue culture and propagation system of Gentiana scabra Bunge. Med Plant 1(4):13-15

Yamada Y, Shoyama Y, Nishioka I, Kohda H, Namera A, Okamoto T (1991) Clonal micropropagation of Gentiana scabra Bunge var. buergeri Maxim. and examination of the homogeneity concerning the gentiopicroside content. Chem Pharm Bull 39(1):204-206

\section{doi:10.1186/s40529-014-0056-4}

Cite this article as: Huang et al.: In vitro propagation of Gentiana scabra Bunge - an important medicinal plant in the Chinese system of medicines. Botanical Studies 2014 55:56.

\section{Submit your manuscript to a SpringerOpen ${ }^{\circ}$ journal and benefit from:}

- Convenient online submission

- Rigorous peer review

- Immediate publication on acceptance

- Open access: articles freely available online

- High visibility within the field

- Retaining the copyright to your article

Submit your next manuscript at springeropen.com 